HOW Journal (Colombian Association of Teachers of English). No. 13. (ISSN 0120-5927) (pp. 7-30). 2006.

APA citation style: Benavides B., Jorge E. (2006). The Effects of the Multimedia 'English Discoveries' Program on the Learning of Five Different Language Skills with High School Students in Pasto. HOW, A Colombian Journal for Teachers of English (13), 730.

\title{
The Effects of the Multimedia 'English Discoveries' Program on the Learning of Five Different Language Skills with High School Students ${ }^{1}$
}

\author{
Jorge E. Benavides B. (joelbebu@gmail.com) \\ Departamento de Lingüística e Idiomas \\ Universidad de Nariño, San Juan de Pasto, Colombia
}

\begin{abstract}
This study determines the effects of the application of multimedia technology Computer-Assisted language learning (CALL) in the development of five language skills using 'English Discoveries'. It shows that the effects of multimedia materials for language learning are not necessarily better as a whole, but different from those obtained in traditional classroom work. Only two of the five variables showed significant differences in favor of the use of Multimedia: pronunciation and oral production. However, grammar showed opposite results. The teachers' and students' reactions suggest the need to adapt their roles to the new context in the future use of CALL and multimedia. The high level of acceptance of this type of materials by the students shows the need for more research and better adaptation of activities to the new context.
\end{abstract}

Keywords: Computer-Assisted Language Learning, (CALL), multimedia materials, Foreign Language Learning, English as a foreign language, new information and communication technologies (NICT).

\footnotetext{
${ }^{1}$ This research study was accomplished through an agreement between the Instituto Nacional de Educación Media (INEM) from La Ciudad de San Juan de Pasto and La Universidad de Nariño in association with the Interdisciplinary Research Group TICED from the same University. The INEM institute provided the subjects (eight groups of students and teachers) both from morning and afternoon schedules and the different facilities.
} 
HOW Journal (Colombian Association of Teachers of English). No. 13. (ISSN 0120-5927) (pp. 7-30).

2006.

\section{The Problem}

\subsection{Antecedents}

The Colombian National Ministry of Education donated complete Multimedia laboratories, initially called 'Bilingual Classrooms' to more than a thousand high school institutions since about ten years ago with the purpose of introducing CALL in language teaching and learning. Recently, the objective has been reformulated as a means to introduce computer literacy and the concept of the new information and communication technologies (NICT) in education not only for the students but also for the teachers, the administrative staff and the educative community as a whole. The government sought to pave the way for teachers and students to use information technology and multimedia CALL materials in order to understand new teaching and learning strategies and new pedagogical issues in the classroom.

\subsection{Problem statement}

It is normal that a lot of people experience a great degree of excitement generated by the new and fast technological development and the need to think how 'technological innovation' would fit in the existing educational system. This has resulted in a situation where most energy has been spent in the technology itself and not in the use of it. The resulting danger for people is that they are usually misled by uncontrolled enthusiasm to the point of becoming unconditional advocates of technology for almost all problems in education. It is then important to concentrate in the real purpose of the use of technology and determine if the amount of time, investment and energy is worth the effort.

Since foreign language learning was an area where hardware and software were already available in most high schools in the country and that there was a need of starting a research program on the real effects of Information and Communication Technology applied to language learning, we first needed to know about the kind of activities that were considered productive, interesting and beneficial for foreign language learning for our students. Using the multimedia program 'English Discoveries' was one of the ways available for this task. 
HOW Journal (Colombian Association of Teachers of English). No. 13. (ISSN 0120-5927) (pp. 7-30).

2006.

\subsection{The research question}

The formal research question was stated as follows: What are the effects of the use of 'English Discoveries' as a multimedia program on the learning of English as a foreign language in skills such as vocabulary, grammar, reading comprehension, pronunciation and oral production with high school students?

\subsection{Hypothesis}

For the sake of the neutrality of the study a null hypothesis was formulated: that there is no difference in the learning of language skills using multimedia materials compared to what is usually done in normal classroom instruction with traditional materials like the textbook. Then the aim of the study is to reject the null hypothesis, and look for the direction of alternate ones.

\subsection{Objectives}

The main objective of this study was to determine the level of learning of five different language skills using 'English Discoveries'.

Other more specific objectives were:

- To describe the context of interaction and participation of the students

- To identify of behavior of teachers in this teaching and learning context

- To determine the students' level of acceptance of multimedia CALL materials.

\section{Review of the Literature}

Every new situation of teaching and learning where the new information and communication technologies are introduced seems to imply an increase of attention from the students' part, thereby directly affecting interest, concentration and cognitive effort, and eventually the results in learning, according to what Benavides (2001) found in a first stage of needs analysis on this topic. This aspect could be more intense if we consider the area of Multimedia where the integration of different media can be more attractive given its new technological characteristics. Different analyses point in the 
HOW Journal (Colombian Association of Teachers of English). No. 13. (ISSN 0120-5927) (pp. 7-30). 2006.

direction of positive cognitive effects of the media and the good possibilities of interaction with the materials (Pusack and Otto, 1990; Borras, 1993). However, the research literature in this area is no consistent especially when speaking of advantages, benefits and improvement of learning using multimedia materials.

\subsection{Research in Computer Assisted Language Learning (CALL)}

Blyth (1999) found that a successful implementation of pedagogical approaches of technology in language learning activities had to consider learning contexts and the student's socio cultural environment. In other words, students coming from a traditional learning context based on textbooks and classroom work found a lot of difficulties to adapt to multimedia CALL technology (based on the interaction and communication with media).

In the field of Multimedia use which is one of the latest technological developments in CALL, the design of pedagogically sound materials and activities related to the students social needs was a turning point for the specialists who questioned the real effect of multimedia in language learning. Hoven (1999) proposed an instructional design with socio-cultural content for multimedia use in which communication and interaction among users were emphasized. Others like Watts (1997) were concerned with the lack of curricular design for the teachers, and centered their attention to activities based on the students' use of technology. Hemard (1997) used hypermedia as a basis for his proposal of curricular design related to the student's needs and the real context of participants: instructors, students and the whole community. However, the one who best interpreted the needs in the field of CALL in the sense of the appropriation of a theoretical and pedagogical foundation was Chapelle (1998) who suggested a theoretical approach based on the acquisition of language taking into account multimedia materials, its interactive characteristics and the integration of media.

The revision made by Light (1993) of quantitative and qualitative research in this field showed that teachers needed to reconsider their role if the goal of education is to make learning more dependent on the interaction between students and materials. This convinced researchers to think that collaborative learning integrated the social component sought by Vygotsky and the 
HOW Journal (Colombian Association of Teachers of English). No. 13. (ISSN 0120-5927) (pp. 7-30). 2006.

emphasis on group work when using CALL for learning purposes, especially in the first stages of the process.

\subsection{Previous research in CALL}

Research has shown that activities which integrate a combination of technology with interactive tasks would help provide a positive context for language learning (Chaves, 1990). Research on oral communication has been scarce for the most part in CALL. However, there are references of studies done in high school (Gonzalez-Edfelt, 1990) where students produced more quantity of discussion on reading materials that they had to do as part of the treatment using CALL materials. These studies suggested that independently from technology, discussion with communicative intension, in the sense that the students had to say something interesting could promote oral production. In this same context it was found that multimedia programs allowed the increase of communicative exchanges among the students (Borras, 1993).

Concerning listening comprehension and pronunciation, research showed advantages of multimedia technology far better than the traditional audio and video work in a language lab, but results were not consistently conclusive regarding classroom work. Multimedia technology allowed for a lot more different interaction modalities and could fit different learning styles. Autonomous and responsible learning originated when technology was taken as a means of interactive practice for students developing their skills according to their own pace and learning styles (Light, 1993). However, the students' attraction for the novelty and the high physical validity of multimedia CALL materials could be one of the intervening variables affecting the results.

Regarding the effects of CALL compared to traditional classroom instruction only a few studies have been conducted in order to determine their characteristics and their best possible use. Studies such as those by Chang \& Smith (1991) found no difference in terms of linguistic gains between students working in pairs and students working alone, using new technologies and the traditional classroom materials. In other studies, the use of CALL materials was not enough if no appropriate feedback was provided. There were reasons to believe that CALL still lacked the power of human feedback like that of the teacher (Sciarone \& Meijer, 1993). On the other hand, Nagata (1997) found 
HOW Journal (Colombian Association of Teachers of English). No. 13. (ISSN 0120-5927) (pp. 7-30). 2006.

out that learning situations were extremely important to be oversimplified when comparing students' achievement in learning contexts with and without multimedia. He maintained that different learning situations required different pedagogic approaches and perhaps this is what was missing not only in the context of CALL but also in those in which the use of technology was not considered at all like in a traditional classroom. Consequently, differences in terms of learning were not significant. However, the most important finding was that the teacher needs to assume a role more like that of a facilitator or advisor in the new context rather than that of a guide o director as in traditional classroom work. Regarding vocabulary and reading comprehension, Benavides, (1998a, 1998b) found a positive correlation between reading speed, comprehension and vocabulary learning working with university students and using CALL materials, along with good levels of interest, attention and commitment from the students with the tasks. Concerning the attitudes and reactions of students and the use of technology most students perceived the use of CALL as something linguistically and affectively advantageous independently of the type of activity or design (Beauvois \& Eledge, 1996).

\subsection{Multimedia CALL and Interactive learning}

The term 'interactive' referred to multimedia is associated to the process by which materials are the means to emphasize students' performance in developing language skills when they make sense of what they do in their own learning context.

With the fast development of CALL materials and the availability of different multimedia programs for almost every language skill there were new ways of doing things in language learning. With the interactive use of multimedia materials the range of new possibilities of adaptation and use by teachers and students was wider. Pusack \& Otto (1990) found that both teachers and students displayed more strategies for adapting to multimedia materials when working with integrated language skills. This has resulted in practical work seeking to adapt to changing conditions without losing perspective of language education goals. The use of multimedia materials with the integration of interactive capabilities has increased the interest in varied types of application in real language development settings. For instance, Liu (1994) discussed the learning of vocabulary using multimedia; Chun \& Plass (1997) approached the 
HOW Journal (Colombian Association of Teachers of English). No. 13. (ISSN 0120-5927) (pp. 7-30). 2006.

learning of reading and textual comprehension; Kramsch \& Andersen (1999) dealt with the capabilities of multimedia to the comprehension of sociocultural patterns. They all found advantages of multimedia CALL when approaches for specific contexts (particular to those of students and teachers' interests) were taken into account.

With the incorporation of digital voice in multimedia applications the practice of phonetic, phonological and communicative aspects of language has enriched the foreign language learning arena. This new form of interaction for listening comprehension and oral production with multimedia materials has been researched with promising results by Ehsani \& Knodt, (1998) who found a positive correlation between learning gains in listening and oral production and exposure to digitalized voice and its manipulation by the students. Using multimedia telematics, like the Internet where real time communication tasks are possible, Cornu et al. (1990) has provided satisfactory ways of more authentic language learning for students in different places.

\section{Methodology}

\subsection{Design and subjects}

A pre-experimental design with experimental and control intact groups was used for this study. The subjects were selected from 'Instituto Nacional de Educación Media' (INEM), a high school institution in the city of San Juan de Pasto, Nariño. Eight groups of approximately 40 students were distributed for the experimental and control groups. The students were adolescents with ages ranging between 10-14 years. They were initiating their sixth grade, making the transition from elementary to high school. Their level of English was that of a true beginner.

\subsection{Materials}

The materials used consisted of 15 workstations with multimedia capabilities, and the program 'English Discoveries' supplied by the National Ministry of Education. The lab had a Compaq Network server linked to the 15 microcomputers configured with basic multimedia devices: speakers, headphones, microphones, mouse and keyboard. 
HOW Journal (Colombian Association of Teachers of English). No. 13. (ISSN 0120-5927) (pp. 7-30).

2006.

'English Discoveries', the multimedia software used for the treatment had nine levels of English as a foreign language starting from 'Basic one' to 'Advanced three' of which only the first two were used for the study. It included activities for listening, speaking, reading, writing, grammar, vocabulary and games. Other materials for the study included handouts for the students, guides and instructions.

\subsection{Instruments}

Five types of tests were designed for pretest and posttest which included vocabulary, grammar, reading comprehension, pronunciation and oral production. The tests underwent pilot testing before their application having students from other courses as subjects.

A scale from cero to five points was used for vocabulary, grammar, and reading comprehension in paper tests whereas another from cero to tree points for the pronunciation and oral production (from not understandable at all, to clearly understandable) in recorded individual test sessions.

The teachers in each of the four experimental groups used field notes throughout the treatment. The field notes included observation guides to identify students' and teachers' reactions during the application of the treatment. University students as research assistants were trained to help the researcher with the observation tasks. Finally, a survey for the students was designed and applied at the end of the treatment.

\subsection{Procedures}

The research process started with a short training course of six hours for the teachers in charge of the four experimental groups on the use of the multimedia materials, the English Discoveries program and the procedures of the research study.

The experimental groups were divided in halves in order for each half to take turns for the use of the computer lab since there were only 15 computers and around 45 students in each group. Up to three students were seated for each 
HOW Journal (Colombian Association of Teachers of English). No. 13. (ISSN 0120-5927) (pp. 7-30).

2006.

computer station. The treatment with 'English Discoveries' was applied during an academic year with the levels of 'Let's start', (as an introduction), 'Basic one' and 'Basic two' in the areas of vocabulary, grammar, reading comprehension, listening and oral production.

Five content modules from 'English Discoveries' were used for the treatment: Exploration, Exposition, Practice, Games and Testing. The main curricular contents and characteristics of the five skills addressed as treatment in this study were:

\section{- Grammar}

There was an explicit focus of these structures in the language section, but they were also integrated throughout Reading, Writing, Speaking, Listening, Vocabulary and games.

\section{- Vocabulary and reading}

Through reading, students could have access to knowledge and information not only about the language, but also about the culture and other related subjects.

The vocabulary and reading sections were to help students to access information about English, as well as to develop specific reading skills and vocabulary learning strategies. The main purpose of the activities of this module was to integrate reading, grammar and vocabulary as extensively as possible.

\section{- Listening comprehension}

The specific listening comprehension skills addressed in this module included listening for main and supporting ideas and for culturally specific information. Like in the previous module, grammar and vocabulary was integrated with listening comprehension 
HOW Journal (Colombian Association of Teachers of English). No. 13. (ISSN 0120-5927) (pp. 7-30). 2006.

\section{- Speaking and pronunciation}

The main purpose of this module was to help students develop their oral production skills, and additionally to improve their pronunciation skills. The computer capabilities for repeating a word or phrase without ever 'getting tired' was a new feature for learning. There were options for practicing: hearing, recording, and playing interactions. Authentic conversational exchanges in real-life settings were presented in the program.

\subsection{Data analysis}

The results from the written and oral tests were evaluated and then displayed in a matrix for each of the eight groups (sixth level at the pretest), and after one academic year (eight months) at the posttest (seventh level). The results for each student in each group in each one of the five variables researched: vocabulary, grammar, reading comprehension, pronunciation and oral production were presented.

Table 1: Distribution of groups in the data matrix
\begin{tabular}{|l|l|l|l|l|}
\hline & EXPERIM. & \multicolumn{2}{l}{ CONTROL } \\
\hline \multirow{2}{*}{ PRETEST } & $6-1$ & $6-2$ & $6-3$ & $6-5$ \\
\cline { 2 - 5 } & $6-12$ & $6-13$ & $6-16$ & $6-17$ \\
\hline \multirow{2}{*}{ POSTTEST } & $7-1$ & $7-2$ & $7-3$ & $7-5$ \\
\cline { 2 - 5 } & $7-12$ & $7-13$ & $7-16$ & $7-17$ \\
\hline
\end{tabular}

The data gathered from tests were analyzed using descriptive and inferential statistics. t- Test for independent samples was used for hypothesis testing and a probability coefficient (or critical value of 0.05 in order to reject the null hypothesis. The survey was analyzed on the basis of percentages and the results from observations had a basic interpretive approach.

\section{Results}

\subsection{Results of the treatment}

The following table presents the results of the tests after the application of the treatment with 'English Discoveries'. 
HOW Journal (Colombian Association of Teachers of English). No. 13. (ISSN 0120-5927) (pp. 7-30). 2006.

Table 2: General results and descriptive statistics

\begin{tabular}{|c|c|c|c|c|c|c|c|c|c|c|}
\hline & \multicolumn{10}{|c|}{ GENERAL } \\
\hline & \multicolumn{5}{|c|}{ EXPERIMENTAL } & \multicolumn{5}{|c|}{ CONTROL } \\
\hline & Voc. & GRA. & REA. & PRO. & OR.P. & Voc. & GRA. & REA. & PRO. & OR.P. \\
\hline Pretest & 4.71 & 4.43 & 2.42 & 0.77 & 0.64 & 5.19 & 5.01 & 2.67 & 0.73 & 0.67 \\
\hline Posttest & 5.76 & 5.13 & 2.92 & 1.07 & 1.03 & 6.06 & 5.72 & 3.06 & 0.90 & 0.92 \\
\hline Difference & +1.05 & +0.70 & +0.50 & +0.30 & +0.39 & +0.87 & +0.71 & +0.39 & +0.17 & +0.25 \\
\hline
\end{tabular}

The control and experimental groups started with differences of $0.48,0.58$ and 0.25 for the control group in the three first skills before the treatment. However, for the last two there seemed to be no difference $(0.04$ and 0.03 for the experimental and control groups respectively). This gives an idea of how the level of English between the two groups was before the treatment.

However, when taking pretest-posttest differences, important gains appeared for the experimental group compared to the ones made by the control group. Although the control groups started with a slight difference in favor in the three first skills, the opposite appeared to be the case for the last two (see differences table No. 1).

At first glance it seemed that the use of multimedia improved the learning of vocabulary and grammar aspects, and reading comprehension to a lesser degree compared to classroom work and traditional materials. But that was not the case when considering the groups posttest differences which was the focus of the statistical analysis for this type of study. The differences were for the control group in the first three skills $(0.3,0.59$, and 0.14 respectively) and (0.17 and 0.11 ) for the experimental group in the last two, but to a lesser degree.

Table 3: t-test for the experimental and control group - independent samples

\begin{tabular}{|l|c|c|c|c|c|c|c|}
\hline & $\begin{array}{c}\text { Experim. } \\
\text { Mean }\end{array}$ & $\begin{array}{c}\text { Control } \\
\text { Mean }\end{array}$ & $\begin{array}{c}\text { Experim. } \\
\text { Std. Dev. }\end{array}$ & $\begin{array}{c}\text { Control } \\
\text { Std. Dev. }\end{array}$ & $\begin{array}{c}\text { t } \\
\text { Value }\end{array}$ & $\begin{array}{c}\text { Degrees } \\
\text { freedom }\end{array}$ & p. \\
\hline Vocabulary & 5.76 & 6.06 & 2.04 & 1.54 & -1.42 & 289 & 0.155002 \\
\hline Grammar & 5.13 & 5.72 & 1.47 & 1.01 & -3.35 & 282 & 0.000888 \\
\hline Reading & 2.92 & 3.06 & 1.17 & 1.14 & -0.96 & 286 & 0.333124 \\
\hline Pronunciation & 1.07 & 0.90 & 0.36 & 1.26 & 4.13 & 280 & 0.000048 \\
\hline O. Production & 1.03 & 0.92 & 0.39 & 0.31 & 2.75 & 279 & 0.006243 \\
\hline
\end{tabular}


HOW Journal (Colombian Association of Teachers of English). No. 13. (ISSN 0120-5927) (pp. 7-30).

2006.

When looking at the results using inferential statistics we could see that the experimental group made more gains than the control group. As shown in table 2, pronunciation and oral production presented significant differences at $p<0.05$ (critical value) for the experimental group thereby rejecting the null hypothesis. Conversely, there was significant difference for the control group in terms of grammar.

Significant differences were not found for the experimental group in the case of vocabulary and reading comprehension. However, there were slight differences for the control group implying that skills such as vocabulary and reading in a CALL context were not as productive as it is in the traditional setting with textbook work as the center of the process. Consequently the null hypothesis was not rejected for vocabulary and reading but only for grammar, as above mentioned, in favor of the control group.

\subsection{Results of observations}

Two types of observation were made throughout the treatment, in order to identify the occurring variables for the students and for the teachers' reactions in the new context.

\subsubsection{Students' observations}

Table 3 indicates the percentage of observations for the students in each variable identified from $1=$ Very Low to $5=$ Very high.

Table 4: Variables identified and number (percentage) of observations

\begin{tabular}{|c|c|c|c|c|c|c|}
\hline & \multirow[t]{2}{*}{ STUDENTS' REACTIONS } & \multicolumn{5}{|c|}{ PERCENTAGE } \\
\hline & & 1 & 2 & 3 & 4 & 5 \\
\hline 1 & Interest & & & 5 & 40 & 55 \\
\hline 2 & Attention & & 5 & 35 & 15 & 45 \\
\hline 3 & Interaction (student-computer) & & 5 & 20 & 35 & 40 \\
\hline 4 & Interaction, (student-student), discussion & 5 & 35 & 15 & 20 & 25 \\
\hline 5 & Peer teaching (collaborative learning) & 15 & 15 & 20 & 25 & 25 \\
\hline 6 & Entertainment & & & 20 & 40 & 40 \\
\hline
\end{tabular}


HOW Journal (Colombian Association of Teachers of English). No. 13. (ISSN 0120-5927) (pp. 7-30).

2006.

The 'interest' variable was determined by the number of times the students asked questions not only to the teacher but also to other students with respect to the tasks performed. In this case the observers rated the occurrence of this variable in a range of 'high' to 'very high' 95\% of the cases making it of a positive kind. Attention followed with $60 \%$ of positive observations, that is, the students' focus on the materials and their activities. Student-computer interaction of $75 \%$ was normally expected since this interaction is considered an important part in the tasks.

In the case of the interaction among students the frequency of positive observations was only of $45 \%$. According to the field notes of the study the purpose of this type of interaction was to exchange information for 'hitting' the 'right answer' during the exercises and tests. In the collaborative aspect of the student's behavior there were contrastive results where $50 \%$ are positive observation and $50 \%$ are negative indicating that this variable was not consistent with the work attributed to multimedia CALL materials and tasks. One important aspect is that much of the observation had to do with the cooperation of the students with respect to their teammates or even with students from other groups. Students with more knowledge about how to do things helped others spontaneously when they realized they were having problems or when they asked questions not only about the workings of the machine (computer, peripheral devices, software, etc.) but also about the language itself. Only a small number of students asked others about the workings of both hardware and software and only at the beginning of the treatment.

The entertaining aspect of the CALL materials was very noticeable during the first half of the process, but especially during the first weeks of the treatment. At the end, the students were more concentrated in the tasks and the novelty of the materials was not an issue for distracting them from the real language tasks.

\subsubsection{Teacher's observations}

Table No. 4 shows the most salient aspects of teachers' participation in the context where CALL multimedia materials and tasks. 
HOW Journal (Colombian Association of Teachers of English). No. 13. (ISSN 0120-5927) (pp. 7-30).

2006.

Table 5 Teacher's observations

\begin{tabular}{|l|r|r|r|r|r|r|}
\hline \multicolumn{1}{|c|}{ TEACHERS' REACTIONS } & \multicolumn{3}{c|}{ PERCENTAGE } \\
\hline $\mathbf{1}$ & Use of resources (dry board, conflict - traditional context) & $\mathbf{1}$ & $\mathbf{2}$ & $\mathbf{3}$ & $\mathbf{4}$ & $\mathbf{5}$ \\
\hline $\mathbf{2}$ & Teacher as a pair, demonstration & 35 & 5 & 10 & 15 \\
\hline $\mathbf{3}$ & Teacher's activity & 5 & 20 & 35 & 35 & 5 \\
\hline $\mathbf{4}$ & Instruction (magisterial instruction) & 15 & 20 & 35 & 30 \\
\hline
\end{tabular}

Four were the most important aspects observed from the teachers. The computer lab was a normal classroom adapted and configured as a computer lab in a 'horse shoe' format with students facing the computers arranged by three of the four walls. On the fourth wall there was a dry board used for the training sessions with the teachers.

At the beginning of the treatment the teachers were usually observed making use of the board as in a normal classroom setting without realizing their students were not facing them when the tasks were being developed. They called their student's attention several times to explain language items and aspects pertaining to the multimedia program. $25 \%$ of the observations were of this type (from 'high' to 'very high') even though teachers were told of the inconveniencies of this particular aspect when the students were at work. The teachers did not often realize they were operating in a different context where they were no longer the center of attention; and most probably they felt threatened by this in many instances when students were exchanging information or interacting.

Two teachers in some instances were seen seating with their students not only for showing them how to do things but also, and most importantly, for listening to the students' explanations on how they were doing at the moment or when they managed to come up with something different of what was planned. The teachers in this case were seen as peers in the learning process. $40 \%$ of the occurrences were rated as 'high' and 'very high'. The activity of the teacher was observed to be positive $65 \%$ of the cases. This implied that he was not passive in this new context. The teacher's activity seemed to increase when groups were working. The teacher was seen constantly moving from one team to another observing what they were doing and whenever they called him to see something particular happening on the screen of the monitor. 
HOW Journal (Colombian Association of Teachers of English). No. 13. (ISSN 0120-5927) (pp. 7-30).

2006.

The last variable observed from the teachers (very much related to the first one) can give us an idea of how the role of the teacher was changing. The magisterial role of the teacher was seen as such $30 \%$ of the observations in the CALL context whereas $55 \%$ of the cases were observed as non-magisterial, that is, different from that of the normal classroom setting. This could be an indication of where the role of the teacher is heading in this new context.

\subsection{Results of the survey ${ }^{2}$}

The following were the results of a 10 question survey applied to the students at the end of the treatment.

1. How useful do you think English Discoveries is for language learning?

\begin{tabular}{|c|c|c|c|c|}
\hline VERY GOOD & GOOD & FAIR & BAD & TOTAL \\
\hline 66.5 & 30.5 & 2.9 & 0.0 & $100 \%$ \\
\hline
\end{tabular}

2. How much do you think you learned from English Discoveries?

\begin{tabular}{|c|c|c|c|c|}
\hline VERY MUCH & FAIRLY & LITTLE & NOTHING & TOTAL \\
\hline 50.1 & 34.2 & 10.3 & 5.3 & $100 \%$ \\
\hline
\end{tabular}

3. How much did you like working with English Discoveries?

\begin{tabular}{|c|c|c|c|}
\hline VERY MUCH & FAIRLY & LITTLE & TOTAL \\
\hline 85.5 & 10.8 & 3.6 & $100 \%$ \\
\hline
\end{tabular}

4. How much do you think the teacher was necessary in the lab?

\begin{tabular}{|c|c|c|c|c|}
\hline $\begin{array}{c}\text { Very } \\
\text { Necessary }\end{array}$ & Necessary & $\begin{array}{c}\text { Little } \\
\text { Necessary }\end{array}$ & $\begin{array}{c}\text { Not } \\
\text { Necessary }\end{array}$ & TOTAL \\
\hline 26.4 & 39.6 & 31.7 & 2.3 & $100 \%$ \\
\hline
\end{tabular}

\footnotetext{
${ }^{2}$ The questions in the survey were given in Spanish. They have been translated here for publishing reasons and convenience of the target audience: English students and teachers and foreign language specialists. The design was originally based on discussions among the participant teachers and the researcher taking into account the experience of the former to evaluate their students and some feedback from the latter.
} 
HOW Journal (Colombian Association of Teachers of English). No. 13. (ISSN 0120-5927) (pp. 7-30). 2006.

5. Would you like to continue working with English Discoveries?

\begin{tabular}{|c|c|c|}
\hline YES & NO & TOTAL \\
\hline 97.0 & 2.9 & $100 \%$ \\
\hline
\end{tabular}

6. Do you think there should be more time to work with English Discoveries?

\begin{tabular}{|c|c|c|}
\hline YES & NO & TOTAL \\
\hline 90.4 & 9.6 & $100 \%$ \\
\hline
\end{tabular}

7. Do you think it is better to work in a GROUP or ALONE?

\begin{tabular}{|c|c|c|}
\hline GROUP & ALONE & TOTAL \\
\hline 40.9 & 59.0 & $100 \%$ \\
\hline
\end{tabular}

8. Was working with English Discoveries EASY or DIFFICULT?

\begin{tabular}{|c|c|c|}
\hline EASY & DIFFICULT & TOTAL \\
\hline 86.5 & 13.4 & $100 \%$ \\
\hline
\end{tabular}

9. Which language skills do you think you learned the most?

\begin{tabular}{|c|c|c|c|c|c|}
\hline Vocabulary & Grammar & Reading & Pronunciation & Oral Production & TOTAL \\
\hline 35.5 & 10.2 & 16.3 & 22.0 & 16.4 & $100 \%$ \\
\hline
\end{tabular}

10. What kind of difficulties did you experience?

\begin{tabular}{|c|l|l|l|l|l|l|l|l|}
\hline Noise & $\begin{array}{l}\text { Light } \\
\text { conditions }\end{array}$ & $\begin{array}{l}\text { Not } \\
\text { enough } \\
\text { Computers }\end{array}$ & $\begin{array}{l}\text { Missing } \\
\text { Microphone } \\
\text { headphones }\end{array}$ & $\begin{array}{l}\text { Malfunc- } \\
\text { tion }\end{array}$ & Discipline & $\begin{array}{l}\text { Reduced } \\
\text { Space }\end{array}$ & Other & TOTAL \\
\hline 10.6 & 5.6 & 23.7 & 33.8 & 8.2 & 7.6 & 10.5 & 0.0 & $100 \%$ \\
\hline
\end{tabular}

The overall results of the survey indicated the high acceptance level of the students for the multimedia CALL materials and the tasks developed with the English Discoveries program. The fact that they expressed that they actually learned with these materials, the specific skills and the amount of learning, among other things, was consistent with the results of this study. Vocabulary 
HOW Journal (Colombian Association of Teachers of English). No. 13. (ISSN 0120-5927) (pp. 7-30). 2006.

items which students heard, repeated, recorded, evaluated, and recycled can be associated to pronunciation which is the skill they developed the most.

\subsection{Discussion}

It can be stated that it is the use of materials and the type of activities, and not technology in itself what makes the difference in learning in CALL when these are authentic and interesting enough to promote learning. This is consistent with Sciarone \& Meijer (1993) in the sense that we can take advantage of the capabilities of technology for the design of pedagogically sound activities which promote language learning. In addition, as stated by Nagata (1997) dealing with different learning situations (with and without multimedia) require different pedagogical approaches and these are too important to be oversimplified in comparing CALL to traditional classroom work. Specific instances of multimedia CALL in connection with the design of different kind of activities taking the context into consideration would allow a more appropriate use of multimedia technology by teachers and students for the development of specific linguistic skills, like listening, pronunciation and oral production in the case of this study, as attested by Ehsani \& Knodt, (1998).

The interaction achieved between students and multimedia materials and among students was always focusing the development of particular language skills. The generalized idea that technology and more specifically, information and communication technology would prevent the student's commitment with interactive communicative activities seems not the have solid empirical basis as it is shown in this study. When CALL activities based on multimedia technology seek to achieve learning objectives based on the development of interactive language skills the results can be promising. This supports the findings by Gonzalez-Edfelt, (1990) \& Borras (1993) regarding the type of interaction that can be achieved with the use of multimedia and the fostering of communicative exchange in the area of language learning. The students not only completed their tasks with the computer but also interacted with their teammates and with other groups through the materials involving themselves in learning activities. This statement would be supported by the collaborative behavior displayed by the students in this study. The interaction that could be promoted by the multimedia mediated activities such as those investigated by Borras, (1993) with respect to communicative exchanges would justify a closer 
HOW Journal (Colombian Association of Teachers of English). No. 13. (ISSN 0120-5927) (pp. 7-30). 2006.

look at the possibilities of using technology for communicative purposes in foreign language learning.

Regarding the role of students, teachers and materials in a multimedia CALL context we can state that despite the fact that this was a rather new environment for the students in foreign language learning they never failed to show excellent disposition to work. Even though the results were not conclusive enough as a whole in favor of Multimedia CALL there seems to be promising areas of pedagogical value in the development of certain language skills as evidence in this study. This would support studies such as Blythe (1999) \& Chavez (1999) in which learning contexts, the cultural environment and the relation among teachers and students have to be taken into account for a successful integration of multimedia CALL learning activities. The roles of teachers, students and materials have to be accommodated to this new context. Multimedia CALL technology can make these roles change in the direction of a different kind of interaction among students, teachers, and materials.

\section{Conclusions, Implications and Suggestions}

The first conclusion from this study is that the application of multimedia was not significantly better in terms of language learning as a whole since only two of the five skills showed significant differences for the treatment: pronunciation and oral production. There is no concluding finding in this study regarding the general effect of multimedia on language learning apart from the two above mentioned skills and the high levels of acceptance of the materials by the students as it was stated in the survey.

The fact that one of the skills -grammar- was significantly positive in learning without multimedia, that is, without the treatment, provides arguments against the claim that multimedia CALL is more effective in language learning as a whole. It can be stated in this case that the effects of multimedia are only positive in certain linguistic domains confirming the findings of Chang \& Smith (1991) where no significant differences were found for CALL in an integral way compared to the results of traditional classroom work. 
HOW Journal (Colombian Association of Teachers of English). No. 13. (ISSN 0120-5927) (pp. 7-30). 2006.

It is suggested that the significant differences in learning in two of the five variables could have been the result of the type of activities performed by the students where the main features of multimedia were emphasized, that is, the strength of interactive capabilities of multimedia, the manipulation of sound and voice patterns -somewhat reminiscent to what was done in a language laboratory. The development of listening, pronunciation, and oral production were the aspects of multimedia CALL that best fit the interest, motivation and commitment of students in the tasks. Some of the advantages of the media integration using computers was the possibility of seeing and listening the oral exchanges in the foreign language controlled by the students themselves. They listened at will, the times they wanted, recorded their performances over the microphone, listened to them, compared them against the original exchanges of the digitized 'native speakers', and evaluated them to restart the process when they decided not enough quality was achieved. The exposition to the native speaking sound patterns and communicative exchanges was determinant for the quality of tasks achieved by the students in the CALL context. Additionally, the reduction of pressure and anxiety levels of having to speak in front of the whole class when they thought not enough practice and quality was achieved could have played an important role in achieving good oral production and pronunciation.

The levels of interest, attention, interaction and entertainment of multimedia technology show that a high degree of acceptance was achieved and that the use of multimedia technology is seen as highly positive as stated by the students' responses in the survey. This confirms the intuition of people about the positive and open attitude towards technology especially by young people. We can take advantage of this high physical validity for learning purposes in general and for the development of language skills in particular.

It is very important to consider the fact that for many students the CALL context with English Discoveries was completely new, but even so, there were quite a few students who knew about computers and the basics of operating the machine and the software. It seems that the world we live in has made computer literacy, competence and performance something which the students bring to school from their homes and in a way from their life's own experiences. This type of knowledge is no longer a product of schools but something that students actually bring to classrooms from today's 
HOW Journal (Colombian Association of Teachers of English). No. 13. (ISSN 0120-5927) (pp. 7-30). 2006.

technologically oriented culture. The evidence is their high degree of accommodation to the new learning context and their outstanding performance in learning tasks to the point that even teachers were overwhelmed by their student's versatile competence with the new information and communication technologies.

The role of the teacher in this new learning context seems to be taking a rather different way compared to that of the traditional classroom. His role as facilitator can be seen as emerging in the context of multimedia CALL. This implies a change of attitude from the teacher's part since in the new context he starts realizing he is no longer the center of attention physically and conceptually. The students are facing something else and failure to recognize this as a fact in a CALL setting would lead to conflict and frustration by the teachers and interruption and loss of motivation by the students.

The implications of this study are mainly directed to the integration of multimedia technology and CALL where a good amount of investment and effort has been made. According to the National Ministry of Education, around 50 high school institutions have been equipped with computer labs for educational purposes and many more institutions with the English Discoveries software for English Language Learning in Nariño ${ }^{3}$. However, we can ask ourselves $\dot{c}$ is this investment equaled with the investment in pedagogical training? Is there a research program behind the integration of Information and communication technology as support for its more appropriate use? Are teachers trained for their involvement in research in this area for its pedagogical development? We believe that very little effort has been put into this technological appropriation in language education.

There is need to emphasize research work for a better understanding of how CALL materials can improve language learning. The integration of research in CALL must be a strong commitment for the pedagogical advancement in the

\footnotetext{
${ }^{3}$ This information was retrieved in Bogotá from the secretary of the 'PROGRAMA DE NUEVAS TECNOLOGIAS: FASE II', and the starting 'PROGRAMA NACIONAL DE BILINGÜISMO' in the Ministerio de Educación Nacional. The document includes information concerning the computer laboratories and the software 'English Discoveries' assigned to El Departamento de Nariño for each school in its municipality. The institutions of the capital, San Juan de Pasto, received 24 computer labs and the software (first and second stages).
} 
HOW Journal (Colombian Association of Teachers of English). No. 13. (ISSN 0120-5927) (pp. 7-30). 2006.

area of foreign language learning where we already have the infrastructure made available by the government. It is also important that the language departments from the different universities in the country take the challenge posed to language education by the new information and communication technologies regarding the formation of future educators for who CALL will be an important issue in their academic and professional activities. We can still ask ourselves ¿Are the new language teaching promotions prepared to face the new technological context of language teaching and learning that is available in most institutions of basic education? The possibilities of finding fully equipped institutions with CALL materials in these fast-changing and technologically-oriented times are very high.

It is important not to make the same mistakes made with the introduction of new technology in the classroom where massive work was implemented without research support and without the necessary critical reflection by the teachers. We need to make sure the university and the foreign language programs are working collaboratively with other institutions in the different levels of education at regional and national levels so that the integration of CALL can be profitable for the community as a whole. We need to be open to technology, but also critically and constructively reflective about it through exploration and research for its pedagogical development.

\section{References}

Beauvois, M. H., \& Eledge, J. (1996). Personality types and megabytes: Student attitudes toward computer mediated communication (CMC) in the language classroom. CALICO Journal 13(2\&3), 27-46.

Benavides B., Jorge E. (1998a). El Computador como modo de Presentación de la Lectura en Inglés. UNED. Universidad de Nariño.

Benavides B., Jorge E. (1998b). El Computador en el Desarrollo de la Lectura en Inglés. San Juan de Pasto: Editorial La Hormiga.

Benavides B., Jorge E. (2001). Análisis de Necesidades en Informática Educativa para Capacitación y Desarrollo Pedagógico en el Nivel de Básica Secundaria. Universidad de Nariño (Informe final de investigación. Mimeo). 
HOW Journal (Colombian Association of Teachers of English). No. 13. (ISSN 0120-5927) (pp. 7-30). 2006.

Blyth, C. (1999). Implementing technology in the foreign language curriculum: Redefining the boundaries between language and culture. Journal of Educational Computing Research, 20(1), 39-58.

Borras, I. (1993).Developing and Assessing Practicing Spoken French: A multimedia program for improving speaking skills. Educational Technology Research and Development, 41(4), 91-103.

Chang, K.-Y. R., \& Smith, W E (1991). Cooperative learning and CALL/ IVD in beginning Spanish: An experiment. Modern Language Journal, 75(2), 205-211.

Chapelle, C. (1998). Multimedia CALL: Lessons to be learned from research on instructed SLA. Language Learning and Technology, 2(1), 22-34. http://It.msu.edu/vol2numl/article 1 /index.html.

Chavez, R. (1990). The development of story writing within an IBM writing to read program lab among language minority students: Preliminary findings. Computers in the Schools, 7(1-2), 121-144.

Chun, D., \& Plass, J. (1997). Research on text comprehension in multimedia environments. Language Learning and Technology, 1(1), 60-81. http://Ilt.msu.edu/voll num l/chun-plass/default.html.

Cornu, A. M., Decker, B., Rosseel, P., \& Vanderheiden, M. (1990). Investigating the teaching of writing techniques in a foreign language: A pedagogical issue. System, 18(3), 361-372.

Ehsani, F, \& Knodt, E. (1998). Speech technology in computer-aided language learning: Strengths and limitations of a new CALL paradigm. Language

Gonzalez-Edfelt, N. (1990). Oral interaction and collaboration at the computer: Learning English as a second language with the help of your peers. Computers in the Schools, 70-2), 53-90.

Hemard, D. P (1997). Design principles and guidelines for authoring hypermedia language learning applications. System, 25(1), 9-27.

Hoven, D. (1999). A model for listening and viewing comprehension in multimedia environments. Language Learning and Technology, 3(1), 88103. Available: http://It.msu.edu/vol3numl/hoven/index.html.

Kramsch, C., \& Andersen, R. (1999). Teaching text and context through multimedia. Language Learning and Technology, 2(2), 31-42. http:// Ilt.msu.edu/vol2num2/article 1 /index.html.

Light, P. (1993). Collaborative Learning with Computers. In P. Crimshaw. (Ed.) Language classrooms and computers. London: Routledge. 
HOW Journal (Colombian Association of Teachers of English). No. 13. (ISSN 0120-5927) (pp. 7-30). 2006.

Liu, M. (1994). Hypermedia assisted instruction and second language learning: A semantic-network-based approach. Computers in the Schools, 10(3-4), 293-312.

Nagata, N. (1997). The effectiveness of computer-assisted metalinguistic instruction: A case study in Japanese. Foreign Language Annals, 30(2), 187-200.

Pusack, J. P., \& Otto, S. K. (1990). Applying instructional technologies. Foreign Language Annals, 23(5), 409-417.

Sciarone, A., \& Meijer, P (1993). How free should students be? A case from CALL: Computer-assisted language learning. Computers and Education, 21(1-2), 95-102.

Watts, N. (1997). A learner-based design model for interactive multimedia language learning packages. System, 25(1), 1-8.

\section{Appendix: Raw Data Matrix Sample}

\begin{tabular}{|c|c|c|c|c|c|c|c|c|c|c|c|c|c|c|c|c|c|c|c|c|c|c|c|c|c|c|c|c|}
\hline \multicolumn{29}{|c|}{ PRETEST } \\
\hline \multicolumn{15}{|c|}{ EXPERIMENTAL } & \multicolumn{14}{|c|}{ CONTROL } \\
\hline \multicolumn{8}{|c|}{$6-1$} & \multicolumn{7}{|c|}{$6-2$} & \multicolumn{7}{|c|}{$6-3$} & \multicolumn{7}{|c|}{$6-5$} \\
\hline No. & VO & GR & RE & PR & $X$ & $\mathrm{OP}$ & $\mathrm{X}$ & VO & GR & RE & PR & $\mathrm{X}$ & OP & $\mathrm{X}$ & VO & GR & RE & PR & $X$ & OP & $X$ & VO & GR & RE & PR & $X$ & OP & $\mathrm{X}$ \\
\hline 1 & 4 & 3 & 2 & 14 & 1,4 & 9 & 0,9 & 8 & 4 & 3 & 9 & 0,9 & 8 & 0,8 & 5 & 5 & 2 & 6 & 0,6 & 10 & 1 & 6 & 8 & 3 & 9 & 0,9 & 17 & 1,7 \\
\hline 2 & 7 & 7 & 4 & 14 & 1,4 & 6 & 0,6 & 5 & 5 & 4 & 6 & 0,6 & 4 & 0,4 & 7 & 9 & 2 & 6 & 0,6 & 4 & 0,4 & 8 & 5 & 4 & 8 & 0,8 & 6 & 0,6 \\
\hline 3 & 4 & 4 & 5 & 12 & 1,2 & 2 & 0,2 & 3 & 4 & 4 & 9 & 0,9 & 8 & 0,8 & 3 & 6 & 4 & 6 & 0,6 & 8 & 0,8 & 4 & 8 & 4 & 8 & 0,8 & 5 & 0,5 \\
\hline 4 & 7 & 6 & 2 & 11 & 1,1 & 2 & 0,2 & 7 & 5 & 1 & 16 & 1,6 & 13 & 1,3 & 6 & 6 & 1 & 4 & 0,4 & 4 & 0,4 & 6 & 5 & 3 & 4 & 0,4 & 6 & 0,6 \\
\hline 5 & 4 & 4 & 3 & 4 & 0,4 & 2 & 0,2 & 4 & 4 & 3 & 6 & 0,6 & 4 & 0,4 & 7 & 5 & 4 & 5 & 0,5 & 4 & 0,4 & 7 & 6 & 2 & 10 & 1 & 7 & 0,7 \\
\hline 6 & 7 & 7 & 2 & 11 & 1,1 & 6 & 0,6 & 5 & 3 & 2 & 16 & 1,6 & 12 & 1,2 & 8 & 4 & 2 & 14 & 1,4 & 9 & 0,9 & 7 & 5 & 4 & 9 & 0,9 & 4 & 0,4 \\
\hline 7 & 5 & 4 & 3 & 12 & 1,2 & 15 & 1,5 & 5 & 4 & 4 & 11 & 1,1 & 7 & 0,7 & 7 & 5 & 3 & 7 & \begin{tabular}{|l}
0,7 \\
\end{tabular} & 9 & 0,9 & 2 & 7 & 3 & 3 & \begin{tabular}{|l}
0,3 \\
\end{tabular} & 8 & 0,8 \\
\hline 8 & 7 & 6 & 4 & 10 & 1 & 12 & 1,2 & 5 & 5 & 2 & 4 & 0,4 & 2 & 0,2 & 5 & 6 & 2 & 3 & 0,3 & 4 & 0,4 & 2 & 8 & 2 & 7 & 0,7 & 3 & 0,3 \\
\hline 9 & 2 & 6 & 3 & 14 & 1,4 & 10 & 1 & 4 & 6 & 1 & 11 & 1,1 & 4 & \begin{tabular}{|l|l} 
\\
\end{tabular} & 5 & 5 & 3 & 5 & \begin{tabular}{|l}
0,5 \\
\end{tabular} & 2 & \begin{tabular}{|l}
0,2 \\
\end{tabular} & 6 & 2 & 3 & 9 & \begin{tabular}{|l}
0,9 \\
\end{tabular} & 8 & 0,8 \\
\hline 10 & 5 & 3 & 1 & 3 & 0,3 & 6 & 0,6 & 5 & 7 & 2 & 5 & \begin{tabular}{|l}
0,5 \\
\end{tabular} & 13 & 1,3 & 8 & 8 & 3 & 8 & 0,8 & 4 & 0,4 & 7 & 5 & 2 & 10 & 1 & 8 & 0,8 \\
\hline 11 & 2 & 4 & 1 & 10 & 1 & 8 & 0,8 & 3 & 4 & 3 & 6 & 0,6 & 3 & 0,3 & 4 & 5 & 2 & 7 & 0,7 & 8 & 0,8 & 6 & 5 & 2 & 8 & \begin{tabular}{|l}
0,8 \\
\end{tabular} & 7 & 0,7 \\
\hline 12 & 5 & 3 & 4 & 9 & 0,9 & 6 & 0,6 & 4 & 5 & 3 & 12 & 1,2 & 4 & 0,4 & 7 & 5 & 1 & 6 & 0,6 & 4 & 0,4 & 6 & 7 & 3 & 19 & 1,9 & 16 & 1,6 \\
\hline 13 & 3 & 7 & 3 & 8 & 0,8 & 6 & 0,6 & 3 & 6 & 3 & 16 & 1,6 & 6 & 0,6 & 5 & 6 & 3 & 5 & 0,5 & 7 & \begin{tabular}{|l}
0,7 \\
\end{tabular} & 6 & 4 & 3 & 13 & 1,3 & 9 & 0,9 \\
\hline 14 & 6 & 4 & 2 & 12 & 1,2 & 7 & 0,7 & 5 & 5 & 2 & 8 & 0,8 & 12 & 1,2 & 7 & 5 & 4 & 5 & 0,5 & 6 & 0,6 & 6 & 6 & 4 & 5 & 0,5 & 5 & 0,5 \\
\hline 15 & 7 & 3 & 1 & 7 & 0,7 & 13 & 1,3 & 3 & 4 & 1 & 6 & 0,6 & 8 & 0,8 & 6 & 5 & 3 & 7 & \begin{tabular}{|l|l|} 
\\
\end{tabular} & 8 & 0,8 & 5 & 3 & 2 & 10 & 1 & 8 & 0,8 \\
\hline 16 & 5 & 3 & 4 & 16 & 1,6 & 18 & 1,8 & 6 & 3 & 1 & 7 & 0,7 & 4 & 0,4 & 8 & 5 & 1 & 4 & 0,4 & 6 & 0,6 & 4 & 4 & 2 & 10 & 1 & 8 & 0,8 \\
\hline 17 & 3 & 6 & 3 & 12 & 1,2 & 8 & 0,8 & 4 & 1 & 2 & 5 & 0,5 & 8 & 0,8 & 9 & 5 & 3 & 9 & 0,9 & 8 & 0,8 & 7 & 4 & 3 & 10 & 1 & 5 & 0,5 \\
\hline 18 & 5 & 4 & 4 & 11 & 1,1 & 12 & 1,2 & 6 & 4 & 4 & 4 & \begin{tabular}{|l}
0,4 \\
\end{tabular} & 4 & \begin{tabular}{|l|l} 
\\
\end{tabular} & 8 & 6 & 3 & 9 & \begin{tabular}{|l}
0,9 \\
\end{tabular} & 10 & 1 & 5 & 5 & 4 & 7 & \begin{tabular}{|l}
0,7 \\
\end{tabular} & 10 & 1 \\
\hline 19 & 6 & 4 & 4 & 12 & 1,2 & 8 & 0,8 & 2 & 5 & 3 & 14 & 1,4 & 6 & 0,6 & 6 & 4 & 3 & 4 & 0,4 & 1 & 0,1 & 6 & 7 & 2 & 9 & 0,9 & 11 & 1,1 \\
\hline 20 & 7 & 2 & 4 & 9 & 0,9 & 8 & 0,8 & 5 & 2 & 3 & 14 & 1,4 & 10 & 1 & 6 & 6 & 1 & 6 & \begin{tabular}{|l}
0,6 \\
\end{tabular} & 4 & 0,4 & 5 & 3 & 2 & 8 & $\mid 0,8$ & 10 & 1 \\
\hline 21 & 6 & 4 & 3 & 12 & 1,2 & 4 & 0,4 & 5 & 3 & 3 & 9 & 0,9 & 8 & 0,8 & 5 & 4 & 3 & 6 & 0,6 & 6 & 0,6 & 6 & 4 & 1 & 13 & 1,3 & 13 & 1,3 \\
\hline 22 & 6 & 2 & 3 & 3 & 0,3 & 10 & 1 & 5 & 4 & 1 & 12 & 1,2 & 4 & 0,4 & 7 & 5 & 5 & 8 & \begin{tabular}{|l}
0,8 \\
\end{tabular} & 4 & 0,4 & 4 & 6 & 2 & 8 & 0,8 & 6 & 0,6 \\
\hline 23 & 6 & 3 & 1 & 6 & 0,6 & 12 & 1,2 & 6 & 2 & 3 & 8 & 0,8 & 7 & 0,7 & 6 & 7 & 4 & 6 & 0,6 & 6 & 0,6 & 6 & 4 & 3 & 7 & 0,7 & 3 & 0,3 \\
\hline 24 & 3 & 4 & 2 & 11 & 1,1 & 11 & 1,1 & 4 & 4 & 2 & 8 & 0,8 & 8 & 0,8 & 6 & 5 & 3 & 8 & \begin{tabular}{|l|l} 
\\
\end{tabular} & 7 & 0,7 & 7 & 6 & 3 & 4 & \begin{tabular}{|l|l} 
\\
\end{tabular} & 8 & | 0,8 \\
\hline
\end{tabular}


HOW Journal (Colombian Association of Teachers of English). No. 13. (ISSN 0120-5927) (pp. 7-30).

2006.

\begin{tabular}{|c|c|c|c|c|c|c|c|c|c|c|c|c|c|c|c|c|c|c|c|c|c|c|c|c|c|c|c|c|}
\hline 25 & 1 & 7 & 3 & 13 & 1,3 & 6 & 0,6 & 5 & 6 & 3 & 8 & 0,8 & 2 & 0,2 & 5 & 6 & 3 & 4 & 0,4 & 4 & 0,4 & 7 & 4 & 3 & 6 & 0,6 & 9 & 0,9 \\
\hline 26 & 3 & 4 & 3 & 6 & 0,6 & 2 & 0,2 & 5 & 5 & 2 & 8 & 0,8 & 6 & 0,6 & 5 & 7 & 3 & 8 & 0,8 & 4 & 0,4 & 7 & 5 & 3 & 4 & 0,4 & 7 & 0,7 \\
\hline 27 & 6 & 4 & 0 & 1 & 0,1 & 13 & 1,3 & 3 & 1 & 2 & 2 & 0,2 & 7 & 0,7 & 4 & 3 & 2 & & & 7 & 0,7 & 7 & 6 & 3 & 3 & 0,3 & 6 & 0,6 \\
\hline 28 & 5 & 4 & 2 & 12 & 1,2 & 10 & 1 & 5 & 4 & 3 & 6 & 0,6 & 8 & 0,8 & 5 & 4 & 4 & & & 4 & 0,4 & 5 & 5 & 3 & 8 & 0,8 & 11 & 1,1 \\
\hline 29 & 4 & 6 & 5 & 11 & 1,1 & 12 & 1,2 & 4 & 5 & 4 & 15 & 1,5 & 6 & 0,6 & 8 & 8 & 2 & & & 9 & 0,9 & 5 & 3 & 3 & 6 & 0,6 & 7 & 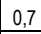 \\
\hline 30 & 6 & 6 & 2 & 12 & 1,2 & 11 & 1,1 & 6 & 5 & 3 & 4 & 0,4 & 2 & 0,2 & 4 & 5 & 3 & & & 4 & 0,4 & 5 & 4 & 2 & 5 & 0,5 & 5 & 0,5 \\
\hline 31 & 5 & 3 & 4 & 11 & 1,1 & 6 & 0,6 & 5 & 4 & 4 & 6 & 0,6 & 8 & 0,8 & 4 & 4 & 1 & & & 4 & 0,4 & 7 & 7 & 2 & 11 & 1,1 & 9 & 0,9 \\
\hline 32 & 4 & 7 & 4 & 11 & 1,1 & 11 & 1,1 & 6 & 3 & 4 & 7 & 0,7 & 6 & 0,6 & 5 & 6 & 3 & & & 6 & 0,6 & 6 & 5 & 1 & 4 & 0,4 & 4 & 0,4 \\
\hline 33 & 3 & 5 & 2 & 7 & 0,7 & 2 & 0,2 & 4 & 5 & 2 & 12 & 1,2 & 6 & 0,6 & 6 & 4 & 4 & & & 5 & 0,5 & 6 & 5 & 2 & 6 & 0,6 & 8 & 0,8 \\
\hline 34 & 5 & 2 & 0 & 8 & 0,8 & 15 & 1,5 & 5 & 3 & 3 & 8 & 0,8 & 14 & 1,4 & 5 & 8 & 2 & & & 7 & 0,7 & 4 & 7 & 3 & 7 & 0,7 & 9 & 0,9 \\
\hline 35 & 5 & 6 & 1 & 7 & 0,7 & 12 & 1,2 & 2 & 5 & 3 & 5 & 0,5 & 12 & 1,2 & 6 & 6 & 2 & & & 2 & 0,2 & 4 & 2 & 3 & 10 & 1 & 6 & 0,6 \\
\hline 36 & 5 & 6 & 5 & 16 & 1,6 & 12 & 1,2 & 6 & 6 & 3 & 7 & 0,7 & 6 & 0,6 & 6 & 5 & 4 & & & 8 & 0,8 & 5 & 4 & 3 & 11 & 1,1 & 14 & 1,4 \\
\hline 37 & 4 & 2 & 2 & 5 & 0,5 & 4 & 0,4 & 5 & 6 & 3 & 2 & 0,2 & 8 & 0,8 & 4 & 4 & 3 & & & 4 & 0,4 & 6 & 6 & 3 & 15 & 1,5 & 8 & 0,8 \\
\hline 38 & 5 & 3 & 2 & 8 & 0,8 & 15 & 1,5 & 5 & 2 & 3 & 10 & 1 & 7 & 0,7 & 8 & 6 & 2 & & & 4 & 0,4 & 7 & 2 & 2 & 9 & 0,9 & 4 & 0,4 \\
\hline 39 & 5 & 5 & 2 & 10 & 1 & 8 & 0,8 & 4 & 3 & 4 & 7 & 0,7 & 4 & 0,4 & 7 & 6 & 4 & & & 6 & 0,6 & 6 & 8 & 3 & 6 & 0,6 & 8 & 0,8 \\
\hline 40 & 0 & 7 & 4 & 10 & 1 & 0 & 0 & 4 & 3 & 3 & 8 & 0,8 & 7 & 0,7 & 7 & 6 & 3 & & & & & 4 & 3 & 4 & 11 & 1,1 & 9 & 0,9 \\
\hline 41 & 4 & 1 & 2 & 10 & 1 & 9 & 0,9 & 3 & 8 & 2 & 2 & 0,2 & 6 & 0,6 & 6 & 5 & 4 & & & & & & & & 10 & 1 & 6 & 0,6 \\
\hline 42 & 5 & 7 & 2 & 10 & 1 & 8 & 0,8 & 5 & 4 & 2 & 8 & 0,8 & 6 & 0,6 & & & & & & & & & & & 9 & 0,9 & 4 & 0,4 \\
\hline 43 & 5 & 6 & 2 & 11 & 1,1 & & & 6 & 6 & 2 & 8 & 0,8 & 6 & 0,6 & & & & & & & & & & & 3 & 0,3 & 2 & 0,2 \\
\hline 44 & & & 2 & & & & & & & & 4 & 0,4 & 8 & 0,8 & & & & & & & & & & & 2 & 0,2 & 6 & 0,6 \\
\hline 45 & & & & & & & & & & & & & 12 & 1,2 & & & & & & & & & & & 7 & 0,7 & 6 & 0,6 \\
\hline 46 & & & & & & & & & & & & & & & & & & & & & & & & & 4 & \begin{tabular}{|l|l}
0,4 \\
\end{tabular} & 9 & \begin{tabular}{|l}
0,9 \\
\end{tabular} \\
\hline SUM & 202 & 194 & 117 & & 42 & & 36 & 200 & 183 & 115 & & 36 & & 31 & 246 & 225 & 114 & & 17 & & 22 & 225 & 203 & 109 & & 37 & & 35 \\
\hline AVG & 4,7 & 4,5 & 2,7 & & 1 & & 0,9 & 4,7 & 4,3 & 2,7 & & 0,8 & & 0,7 & 6 & 5,5 & 2,8 & & 0,6 & & 0,6 & 5,6 & 5,1 & 2,7 & & 0,8 & & 0,8 \\
\hline D.STD. & 1,6 & 1,7 & 1,3 & & 0,3 & & 0,4 & 1,3 & 1,5 & 0,9 & & 0,4 & & 0,3 & 1,4 & 1,3 & 1 & & 0,2 & & 0,2 & 1,4 & 1,7 & 0,8 & & 0,3 & & 0,3 \\
\hline
\end{tabular}

